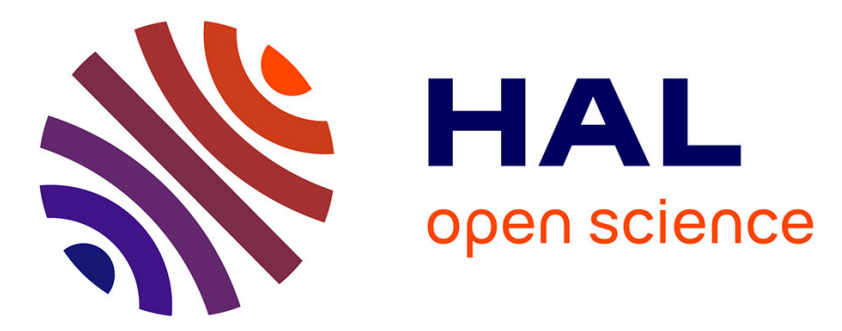

\title{
How to define and use safety indicators to implement an efficient prevention policy
}

Raoul Textoris, Tullio Joseph Tanzi

\section{To cite this version:}

Raoul Textoris, Tullio Joseph Tanzi. How to define and use safety indicators to implement an efficient prevention policy. 6th International Conference on Human System interaction - HSI 2013, Jun 2013, Gdansk, Poland. p. 466-472 - ISBN 978-1-4673-5637-4, 10.1109/HSI.2013.6577866 . hal-00820819

\section{HAL Id: hal-00820819}

\section{https://hal-mines-paristech.archives-ouvertes.fr/hal-00820819}

Submitted on 10 Jun 2013

HAL is a multi-disciplinary open access archive for the deposit and dissemination of scientific research documents, whether they are published or not. The documents may come from teaching and research institutions in France or abroad, or from public or private research centers.
L'archive ouverte pluridisciplinaire HAL, est destinée au dépôt et à la diffusion de documents scientifiques de niveau recherche, publiés ou non, émanant des établissements d'enseignement et de recherche français ou étrangers, des laboratoires publics ou privés. 


\section{How to define and use safety indicators to implement an efficient prevention policy}

\author{
Raoul Textoris
}

L'Oréal Clichy

Centre de Recherche sur les Risques et les Crises, Mines-ParisTech

Sophia Antipolis - France

raoul.textoris@loreal.com

\author{
Tullio J. Tanzi \\ CNRS - LTCI UMR 5141 \\ Centre de Recherche sur les Risques et les Crises, \\ Mines-ParisTech \\ Sophia Antipolis - France \\ tullio.tanzi@mines-paristech.fr
}

\begin{abstract}
In our modern societies, socio-technological systems and human system interactions are taking on a large part in numerous domains such as health, control of risk, people safety, communication, information technologies, and so on. In order to manage such systems, it is necessary to put in place the most relevant indicators. To facilitate decision making in various fields such as people safety and risk management, the definition of indicators generated by such systems is needed in order to deliver the appropriate action plan especially to control occupational accidents.
\end{abstract}

The aim of the article is to present our approach to analyze and define this category of new indicators.

Keywords: Sociological and psychological aspects, measurement systems, safety indicators, risk management.

\section{INTRODUCTION}

Statistics from International Labor Organization and Worldwide Health Organization [1] put in evidence that 2 million occupational fatalities occur each year worldwide (e.g. around 1 fatality every 20 seconds) divided in 1.7 million due to occupational diseases and 0.3 million due to occupational accidents (plus 268 million lost time accidents more than 3 days out of work). To compare with, there were 2 million soldiers killed each year during the First World War that is to say as many as workers killed each year worldwide. Beyond all human and ethic stakes, the economic impact of fatalities at work, estimated to 1250 billion dollars (e.g. $4 \%$ of worldwide GNP), is quite huge. This problem has to be solved globally, either for rich or poor countries. Hubert Curien, a French scientist, liked to say that for industrialized countries, technology and innovation are often considered by public opinion as a risk (like " heaven »). On the contrary for emerging countries, it is a vital opportunity. Each state must build its own history and culture. But we need more solidarity, shared effort and equity in business, while reducing risk at the source. A good example is REACH regulation because even if a new dynamic is complicated to implement, it should be a reference in all other countries so as to reinforce prevention and avoid drifting risks and accidents in developing countries. Behind global figures, we can find several situations worldwide. For instance, occupational fatalities are around: 5500 in the USA, 100000 in China, 6000 in Russia and 40000 in South America... It is still far too much. The importance of safety must be considered as a shared value and a fundamental principle.

\section{SAFETY INDICATORS}

One of the main objectives put in evidence by companies is «zero accident ». It is often merely required by regulation. For instance, in France, companies must prevent any kind of accident whatever means. The motto «zero accident» often corresponds to a very positive commitment, to a high motivation and conviction to implement a system of values and reach very high level of performance. However, we have to be vigilant because some bias can appear. As an example, we can remember the so-called « better, faster, cheaper » programme launched by NASA, considered as one of the root cause of Challenger and Columbia accidents. Each action is multidimensional. Complexity of sociotechnical system can generate bias. We must try to step back, and have in mind that if we don't make decision it is still as if we were taking a decision.

The accident of BP refinery in Texas on March 23rd, 2005 should remain in all memories in order to learn lessons of what happened (15 fatalities, 170 severely injured, 700 million dollars to the victims, 2.3 million for OSHA safety and hygiene violations, plus the ones corresponding to environmental violations).

Baker's report (January, 2007) [2] starts like that: « Other companies and their stakeholders can benefit from our work. We urge these companies to regularly and thoroughly evaluate their safety culture ». As a consequence and following the conclusions of various reports, BP launched several programmes on leadership and on process safety management (PSM) and planned to invest 1 billion dollars over a 5 years period in the refinery. The Group decided to internalize some technical activities that had been outsourced during the past and to reinforce internal expertise. Here can be highlighted a very classical question: could we expect such an accident by meaning of specific indicators? Baker's report indicates: «The literature also suggests and the panel believes that the presence of an effective personal safety 
management system does not ensure the presence of an effective process safety management system. As discussed elsewhere in this report, BP's personal injury rates were not predictive of process safety performance at BP's five US refineries ». There are other comments about this topic: «BP has emphasized personal safety in recent years and has achieved significant improvement in personal safety performance, but BP did not emphasize process safety. BP mistakenly interpreted improving personal injury rates as an indication of acceptable process safety performance at its US refineries. BP's reliance on this data, combined with inadequate process safety understanding, created a false sense of confidence that BP was properly addressing safety risks. The panel further found that process safety leadership appeared to have suffered as a result of high turnover of refinery plant managers ». 8 plant managers were successively hired over a period of 6 years on site composed with $1800 \mathrm{BP}$ staff and 2000 outside workers. BP had launched programmes to improve behavior and risk awareness, which could decrease the conventional frequency rate of lost time accident by $70 \%$. By referring to this only one indicator, one could feel honestly to improve situation.

\section{A. Current indicators}

The Conventional Frequency Rate (CFR) is an indicator used to measure the number of lost time accidents over a period of time per million worked hours. However, even if it is widely used, it does not represent a full control of risk performance especially for major risks, nor even for specific risks. CFR compiles each type of accidents whatever causes, and we all know that to be efficient to prevent accident we must act on causes. We still have to focus on causes, analyze events and manage feedback.

The CFR is the number of lost time accidents over one day over a period of 12 months in general, per million worked hours. The CFR is defined by the ratio:

$$
\mathrm{CFR}=\frac{L T A \cdot 10^{6}}{N W H}
$$

With CFR: Conventional Frequency Rate, LTA: number of lost time accident and NWH : number of worked hours ${ }^{l}$.

Another indicator is the Severity Rate (SR):

$$
\mathrm{SR}=\frac{L D \cdot 10^{3}}{N W H}
$$

\section{With LD: number of days lost}

Using this indicator is not as simple. It is possible to determine the sensitivity factor of CFR versus the size of the sample of people (Table 1). The graph on Fig. 1 determines the impact factor of on lost time accident when the sample is varying between 1 and 5000 .

1 The number of worked hours is calculated by multiplying the number of workers with the average annual working hours of a full time employee.
TABLE 1: SENSITIVITY FACTOR VERSUS THE SIZE OF THE SAMPLE

\begin{tabular}{|l|l|}
\hline \multicolumn{1}{|c|}{ Sample } & \multicolumn{1}{c|}{ Impact factor } \\
\hline 1 & 613,4969325 \\
\hline 2 & 306,7484663 \\
\hline 5 & 122,6993865 \\
\hline 10 & 61,34969325 \\
\hline 50 & 12,26993865 \\
\hline 100 & 6,134969325 \\
\hline 500 & 1,226993865 \\
\hline 1000 & 0,613496933 \\
\hline 5000 & 0,122699387 \\
\hline
\end{tabular}

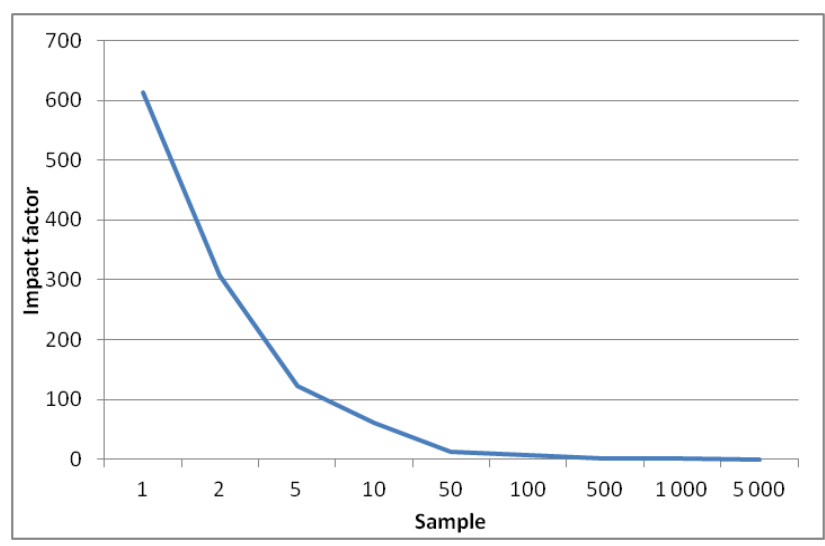

Fig. 1: Indicator of result or follow up [4]

The moment when an accident occurs on the time horizon (usually 12 months) can also have an impact. Let us take an example where a plant has got one accident over a 12 months period. If the accident is occurring in January:

- The CFR in January is 12 times higher than it will be at the end of December.

- The cumulative CFR will be impacted all the yearlong.

If the accident occurs in December, between January and the end of November, the indicator will be equal to zero with a "feeling" to control risks.

In December, the indicator will turn red with the feeling that suddenly the situation was worsen, e.g. before the accident everything seems ok and after the accident everything seems bad.

It is not because we hold the handrail while climbing down the stairs on a tank with flammable solvent that it will not explode as Andrew Hale often says. We must do both: to hold the handrail and to manage other risks as «process » ones. It is also important to step back. For instance, the risk awareness programme to improve vigilance had been launched when they had at the same time shift operators working more than 30 successive 12 hours shifts. The question of global coherence is raised. In addition to that, 300 violations were identified on equipments by several surveys following the accidents and we can remind that the year before the explosion, there were 2 fatalities in the refinery (in 2004). 
Let us consider « classical indicators » for Texas City Explosion. Data for 1999-2009 period are available on BP internet site as well as lots of comments. Let us take a horizon of 4 years before the explosion e.g. 2001-2004 and another horizon of 4 years after the explosion e.g. 2006-2009, the number of killed workers (BP personals and outside workers) has considerably decreased by 23 (from 60 to 37). This result is probably due to specific action plans on corresponding risks. If we want to reduce risks with high potential from severe accidents to fatalities we have to act on the specific root cause of these specific risks (and not only on the causes that have an impact on the CFR).

Regulation in France or in the USA (for instance, OSHA form number 300) demands to publish the CFR. As a consequence CFR must be available. This indicator must be stored and in fact is often used (and still used e.g. anchored bias) as an «absolute» measure of safety performance, as «benchmark » for other companies and is used to define policies and objectives based on "zero" accident motto. CFR can be relevant to measure some situations, but not for others (e.g. for PSM); on a statistical standpoint it can even be non-relevant when accident rate is very low. It is thus important to analyze how organizations work. Usually, companies set annual objectives with a percentage of improvement year by year. We have to spend time to assess how the objectives are pertinent and coherent by years: what is improved year by year is it always coherent on the long term? CFR can be improved for example by implementing behavioral programme that can be useful to some extent, but we have to define the frame and the corresponding limits.

Baker's report (others can be found, e.g. Mogford's report) puts in evidence some important causes: lack of maintenance, lack of process safety management and associated expertise. These causes are not reported in usual scorecards compared to CFR.

\section{B. Edge effects of indicators}

It is possible to improve CFR year by year by working on programme based on behavior and awareness, while at the same moment reducing annual maintenance or training budget or specific expertise that are mandatory for future performance, even for sustained business. This point has especially to be taken into account when considering manager turnover. A too big turn over can introduce strong bias, e.g. to get quick wins only compared to long term actions which are fundamental. The system of annual objectives must take into account those dimensions and must ensure a full coherence between short term and long term objectives. As for example, ergonomic: to avoid hazardous situations that will generate problems in the future (when managers will have turned over). Organizations must ensure short term and long term coherence: both are important and interact.

Global control of risks must be based on prioritizing as regulation is requiring too. When companies want to improve EHS performance, they have to define the right indicators because the top managers will then focus on them. Let us remind the comments from Herbert Simon's economic Nobel Prize: «the most important resource is not information but the awareness of actors ». When top managers are committed to EHS, we must have relevant indicators to assess the efficiency of policies. What is also important is to ask oneself as far as possible and as often as possible the right questions. Then to understand and act in the right direction, as Deming used to say, «Best efforts are not enough; you have to know where to go ».

\section{EXAMPLE: COMPANIES FROM CAC40 STOCK EXCHANGE INDEX}

We made a study to compare CFR and Severity rate for companies belonging to $\mathrm{CAC} 40$ in order to understand the indicators that are used.

Conventional CFR measures the number of lost time accidents per million worked hours over a period of time, usually one year. This definition is used in France and in some other countries. In the USA, the indicator refers to 0.2 million of worked hours. In some companies, there can be used other comparable indicators taking into account other events (first aid ...).

Severity rate measures the number of days out per million worked hours over a period of time usually one year.

These two indicators are measuring the frequency of accidents and their severity. So the greater they are the more accidents are occurring with high consequences in term of number of days out of work. A company that is investing in the control of risk generally is measuring the efficiency of its actions by the improvement that is by reducing these two indicators.

Even if the CFR is widely used within companies, it is a non-trivial measure - including safety specialists. A value of 5 is better than 10 , itself better than 20 , but what is the meaning of this indicator. Another way to try to address the problem is to calculate the CFR of each employee by considering for instance that only had one lost time accident in their whole working life. The orders of magnitude can vary with a factor from 1 to 10 . This demonstrates how it is difficult to give sense to CFR. The result of calculation is around 13.5 in France. If we consider an average of annual working hours with other European countries with USA and Japan, we can determine an average CFR around 10. So it means that within a company with a CFR equals to 10 (that remains at 10) each employee will get injured once in all his working life.

Severity Rate is also hard to understand: what is the meaning? However it is possible to calculate the ratio CFR/SR that determines the number of days off per lost time accident, but it is rarely used. The analysis of global results (see table 2) shows a significant result: transportation activities (aviation, railway and subway) rare gathering data among the highest in term of CFR. 
TABLE 2: THE DATA REFER TO SUSTAINABILITY REPORTS AVAILABLE ON THE INTERNET (2009)

\begin{tabular}{|c|c|c|}
\hline Companies & Safety Indicators & Values \\
\hline \multirow{2}{*}{$\begin{array}{l}\text { Suez environnement } \\
\text { CAC } 40\end{array}$} & CFR & 17.45 \\
\hline & SR & 0.5 \\
\hline \multirow{2}{*}{$\begin{array}{l}\text { Veolia Environnement } \\
\text { CAC40 }\end{array}$} & CFR & 38.1 \\
\hline & SR & 1.63 \\
\hline \multirow{2}{*}{ RATP } & CFR & 38.6 \\
\hline & SR & 1.41 \\
\hline SNCF & CFR & 33.87 \\
\hline Air France & SR & 27.62 \\
\hline KLM & CFR & 21.66 \\
\hline \multirow{2}{*}{ Bouygues CAC40 } & CFR & 12.3 \\
\hline & SR & 0.49 \\
\hline \multirow[t]{2}{*}{ Vinci CAC40 } & CFR & 11.59 \\
\hline & SR & 0.64 \\
\hline Haliburton (USA) & CFR & 4.85 \\
\hline \multirow{2}{*}{ GDF Suez CAC40 } & CFR & 11.2 \\
\hline & SR & 0.44 \\
\hline \multirow{2}{*}{$\begin{array}{l}\text { Schneider Electric } \\
\text { CAC40 }\end{array}$} & CFR & 9.8 \\
\hline & SR & 0.09 \\
\hline \multirow{2}{*}{ EDF CAC40 } & CFR & 6.2 \\
\hline & SR & 0.2 \\
\hline \multirow{2}{*}{ Saint Gobain CAC40 } & CFR & 4.8 \\
\hline & SR & 0.22 \\
\hline \multirow{2}{*}{ Lafarge CAC40 } & CFR & 1.57 \\
\hline & SR & 0.14 \\
\hline L'Oréal CAC40 & Frequency rate & 2.3 \\
\hline Rhodia & Frequency rate & 0.59 \\
\hline
\end{tabular}

\begin{tabular}{|c|c|c|}
\hline & Gravity rate & 0.046 \\
\hline Sanofi Aventis CAC40 & Frequency rate & 2.6 \\
\hline Peugeot CAC40 & Frequency rate & 3.43 \\
\hline Renault CAC40 & Frequency rate & 2 \\
\hline Alcatel Lucent CAC40 & Frequency rate & 1.72 \\
\hline Vivendi CAC40 & Frequency rate & 2.72 \\
\hline $\begin{array}{l}\text { France Télécom } \\
\text { CAC40 }\end{array}$ & Frequency rate & 4.1 \\
\hline $\begin{array}{l}\text { Société générale } \\
\text { CAC40 }\end{array}$ & $\begin{array}{c}\text { Number of paid } \\
\text { day of absence due } \\
\text { to illness }\end{array}$ & $\begin{array}{l}808 \\
334\end{array}$ \\
\hline \multirow[b]{2}{*}{ Crédit agricole $\mathrm{CAC} 40$} & $\begin{array}{c}\text { Number of } \\
\text { accident (France) }\end{array}$ & 1300 \\
\hline & $\begin{array}{c}\text { Number of paid } \\
\text { day of absence due } \\
\text { to illness }\end{array}$ & $\begin{array}{l}726 \\
230\end{array}$ \\
\hline BNP Paribas CAC40 & $\begin{array}{c}\text { Absence rate for } \\
\text { accident }\end{array}$ & 0.09 \\
\hline AXA CAC40 & $\begin{array}{c}\text { Absence rate for } \\
\text { accident }\end{array}$ & 0.02 \\
\hline La Poste & Frequency rate & 24.64 \\
\hline Danone CAC40 & Frequency rate & 5.2 \\
\hline Arcelor Mittal CAC40 & Frequency rate & 2.3 \\
\hline \multirow{2}{*}{ Michelin CAC40 } & Frequency rate & 1.85 \\
\hline & Gravity rate & 0.21 \\
\hline Air Liquide CAC40 & Frequency rate & 1.8 \\
\hline Total CAC40 & Frequency rate & 2.21 \\
\hline \multirow{2}{*}{ Vallourec CAC40 } & Frequency rate & 7.8 \\
\hline & Gravity rate & 0.38 \\
\hline Carrefour CAC40 & $\begin{array}{l}\text { Absence rate for } \\
\text { accident }\end{array}$ & 0.62 \\
\hline \multirow{2}{*}{ Lagardère CAC40 } & Frequency rate & 9.85 \\
\hline & Gravity rate & 0.32 \\
\hline
\end{tabular}


As a comment: if the CFR was measuring by the whole safety performance of a company (as it is often considered), we should be facing big weaknesses in the control of risks of these transportation activities. On the contrary, millions of passengers are travelling safely each year, and those activities, which are one of the most regulated and inspected, are considered as very reliable. To go on further, Air France and KLM, which belong now to the same Group, still have huge differences due to the legal classification of accident between France and Netherlands.

So, barotrauma otitis and back injuries, classified as occupational accidents in France and that represents $40 \%$ of lost time accidents within Air France, are classified as absenteeism for occupational disease within KLM, in compliance with Netherlands regulation. This makes it difficult to compare indicators even within the same Group. We can notice on the other hand that the rate of participation of flying teams in training activities is $100 \%$.

A second point must be highlighted: Companies from CAC40, that have the lower CFR, have the ratio of number of days off per lost time the bigger (around 100 e.g. on average each lost time accident corresponds to more than 3 months off, when those that get the higher CFR get half of this ratio). This clearly shows that by controlling most frequent accidents you do not control the most severe accidents automatically.

Even more important, these two indicators do not take into account fatalities which are the ones to avoid at first.

Furthermore for one company we can determine that for a period of 10 years the duration of days lost per lost time accident (DPLTA)2 is increasing almost continuously from around 30 days to 100 days while CFR is decreasing continuously (see Fig. 2).

It appears that there are fewer accidents but much more severe ones.

Based only on CFR, you could consider that prevention is improving but taking into account DPLTA the prevention is worse.

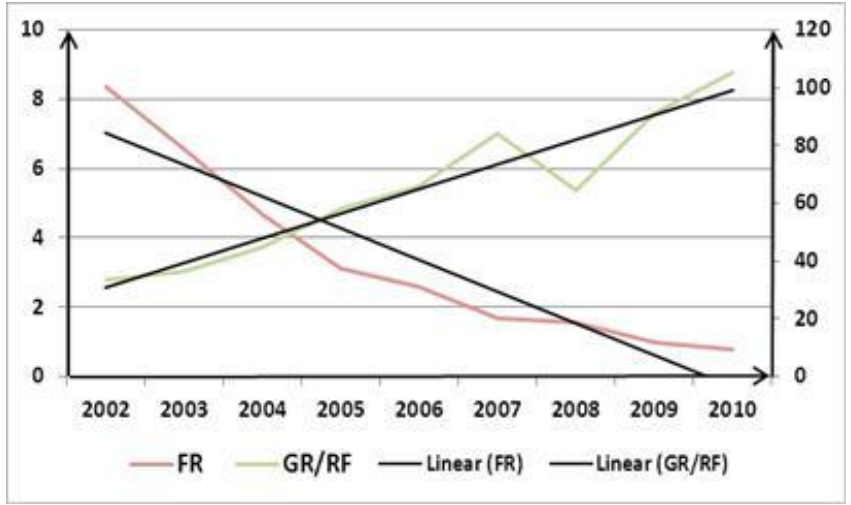

Fig. 2: CFR versus DPLTA

\section{PROPOSAL TO DEFINE A METHODOLOGY TO BUILD INDICATORS}

New indicators must include a management dimension, in the Tanzi and Textoris' study [2012] [4] and Kaplan's study [1992] [5], which corresponds to classical indicators, but equally a piloting dimension that is still to be defined. Difference lies on the fact that information to pilot is directly linked to how to drive action, while management information is dedicated to information structure of the company.

In order to facilitate how to use them, so how to interpret them, they can be organized in synthetic scorecard. Research from Kaplan and Norton on the notion of "balanced scorecard" [5] [Kaplan 92], [6] [Kaplan 96] is a key contribution to our field of study.

More precisely : "a performance indicator that can help a manager, at an individual or more often at a team levels, to pilot the action up to the objective or that can allow to assess the result ..." [7] [Lorino 2003]. So it is not an "absolute" measure, a characteristic of the measured phenomenon independently from the observer. It is built by the actor [8] [Lorino 1995].

We can then define an indicator as so: As a consequence, it is a sophisticated management tool with some specific features. For example:

- The strategic objective to which it is linked, its targets with timeframe and measurable features, the relevant references,

- The clear identification of who is in charge to deliver them, and the one in charge of its performance,

- Frequency and follow up,

- Technical definition : formula and calculation convention, sources of information, ...

- Segmentation modes to decompose aggregated form : geographical data, type of product, center ...

- Presentation (ex: numerical data, tables, graphics, ...) and communication list.

\footnotetext{
${ }^{2}$ DPLTA $=\frac{S R}{C F R \cdot 10^{3}}$

days lost per lost time accident times 1000 eg the severity of each accident.
} 
Such an indicator is composed by two different functions depending on how it is located compared to the action (see Fig. 3). It can be an indicator of result. In that case, it gives an assessment of the final result when the action is completed. But it can also be a follow up indicator. It allows to anticipate or to react on time. By definition, the result indicator comes too late to shift the action.

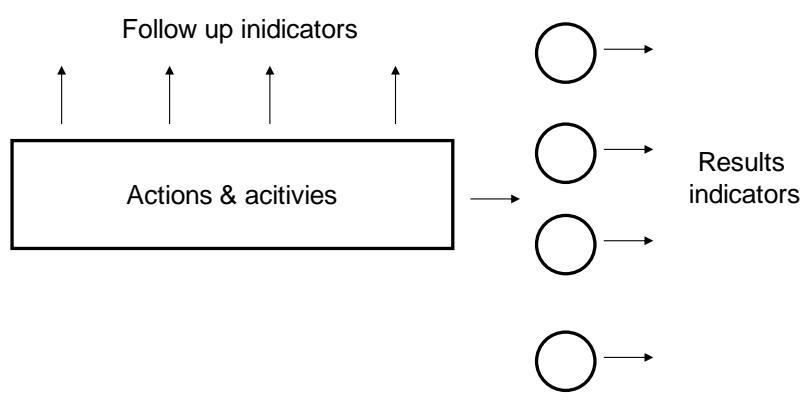

Fig. 3: indicator of result or follow up [4]

The way it is located compared to the structure of power and responsibility gives it also a final duality (Fig. 4). The corresponding reporting gives an indication of the percentage realization of the objectives, which can be considered as a control a posteriori, and the piloting whose objective is to adapt actions in progress.

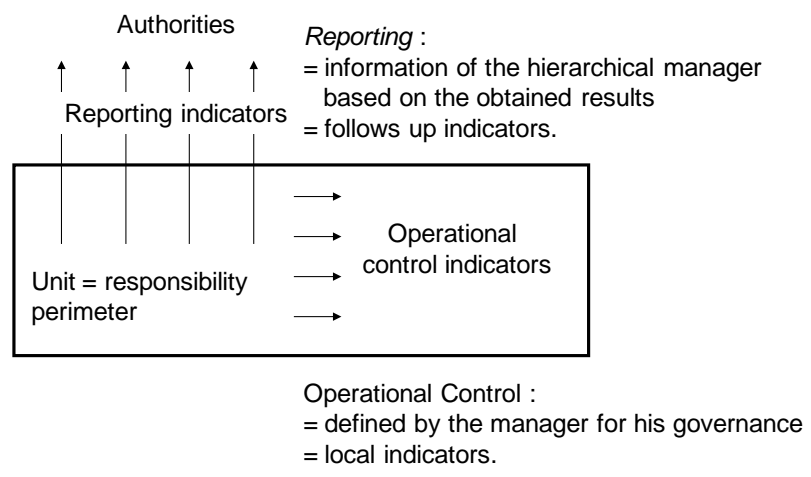

Fig. 4: Leading indicator or reporting [4]

The composition of such an indicator must take into account aspects linked to operational relevance as for example, combining indicator / action, the question of "controllability", and the impact of levers on actions.

It is also necessary to take into account some aspects linked to strategic relevance such as, for example, the association of indicator / objective[9] [Kerr 1975], [10] [Epstein 1998], the measure of the completion of the results (Indicator of result), and data on how actions are implemented (Leading Indicator).

This reflection must be completed with another dimension concerning the cognitive efficiency. Indeed, these indicators are used by the actors in a given context. They influence the action and the way it is understood. It is so necessary to define how to read them, to understand and to interpret as soon as the indicators are designed. It is the only condition to set a frame to take into account the context of the actor, and that is easy to use.

Some questions are rising when we want to define indicators. Do we want to use financial indicators, or nonfinancial, or use a mix of both? If we define non-financial indicators, is it better to valorize the stakes? What is the right number of indicators to get a clear and coherent picture?

It appears necessary to dissociate management indicators and piloting indicators [11] [Hopkins 2007].

The way indicators are organized within a scorecard, for example as for balanced scorecard, makes it possible to have both types of indicators financial and nonfinancial. Indicators are organized in four parts: learning, process, customers and financial aspect. Inside the scorecard, indicators are linked with a causal model.

We have seen previously that indicators can focus on past information as so-called indicators of result (lagging indicator) [Mitchell 1938]. They can also take into account information on current performance that can act on future performance. They are called indicators of action or advanced indicators or piloting indicators or alert indicator (leading indicator) [12] [Mitchell 1938]. Mitchell, in his work [Mitchell 1938], had also defined Coïncident indicator that puts in evidence events almost happening at the same moment (coïncident indicator).

So we can organize indicators within balanced scorecard that makes it possible to have at the same time financial and non-financial indicators.

\section{CONCLUSION}

The various sociotechnical activities need specific control system adapted to the stakes and complexity of their environment in order to reach their goals. In the field of prevention of risks for workers, ethical and human stakes are paramount. Based on statistics from International Labor Organization and Worldwide Health Organization [1], we can give the following data. There are 2000000 fatalities at work each year worldwide divided in 1700000 fatalities due to occupational diseases and 300000 due to occupational accidents (plus 268 million lost time accidents more than 3 days out of work).

To compare with these 2000000 fatalities we can remind other worldwide figures:

- 999000 fatalities on the road ( 1 million).

- 563000 fatalities due to violence ( 1/2 million).

- 502000 fatalities due to war ( 1/2 million).

- 312000 fatalities due to VIH/Aids ( 1/3 million).

Beyond all human and ethic stakes, the economic impact of fatalities at work, estimated to 1250 billion dollars, e.g. $4 \%$ of worldwide GNP, is quite huge.

Politics have to develop strong vision and concrete policies of prevention to solve this very important problem for the whole world. 
When reading various Sustainable Corporate Reports, we can notice that some companies take into account the CFR of outside contractors but this is not generalized. To compare companies using widely subcontractors in a more relevant way this activity would have to be included. Moreover, in order to use statistics properly, we have to be rigorous and do not use data out of their context. Indeed to determine if the CFR is good or not, it can be useful to know the average of companies from the same sector of activity. How can be relevant to compare companies from so different sectors as construction or pharmaceuticals?

Then CFR does not demonstrate necessarily the existence of direct links with efforts invested in safety and health programmes and improvements achieved. We can give the example of AIR France KLM with a CFR equals to 28.62 when the rate of participation of flying teams in training activities is $100 \%$.

Another example, Michelin has got a CFR equals to 1.85 and CFR equals to 0 for 30 of its plants, so the company is one of the leader for manufacturing companies. But Michelin was obliged to put in place other indicators as the rate of participation to preventing actions, because classical indicators as CFR were no more sufficient.

So CFR is one of the most used indicators of the Safety Management System to measure company performance but this indicator has got intrinsic limits. It must then be used with other indicators that demonstrate all together the level of risk control. It should be appropriate to put in place other indicators such as the participation rate or the measure of efficiency with time if we want to demonstrate what makes the system work or result indicators such as the measure of the number of accidents avoided for instance to show the impact of actions.

\section{REFERENCES}

[1] WHO, ILO Department of communication, 2005 http://www.who.int/mediacenter/news/releases/2005/pr18fr/index. htm.

[2] Baker J (2007) The report of the BP US Refineries Independent Safety Review Panel

[3] Juglaret F, Rallo JM, Textoris R, Guarnieri F, Garbolino E (2011) The Contribution of Balanced Scorecards to the Management of Occupational Health and Safety. European Safety and Reliability Conference: Advances in Safety, Reliability and Risk Management, ESREL 2011, Troyes: France

[4] Tanzi TJ, Textoris R, (2012) Using Indicators for System Complex Safety. In Proceedings: $7^{\text {th }}$ International Conference on System Of Systems Engineering - IEEE SOSE $2012-7^{\text {th }}$ International Conference on System Of Systems Engineering IEEE SOSE 2012, Italie

[5] Kaplan R, Norton D (1992) The Balanced Scorecard - Measures that Drive Performances, in Harvard Business Review, Jan-Feb 1992

[6] Kaplan R, Norton D (1996) The Balanced Scorecard, Harvard Business School Press, Boston, USA

[7] Lorino P (2003) Méthode et pratiques de la performance. Le pilotage par les processus et les compétences, Editions d'Organisation, Paris

[8] Lorino P (1995) Comptes et récits de la performance, Editions d'Organisation, Paris

[9] Kerr S (1975) On the folly of rewarding A, While hoping for B Academy of Management Journal, pp 769-783
[10] Epstein M, Manzoni JF (1998) Implementing Corporate Strategy / From Tableaux de Bord to Balanced Scorecards, European Management Journal, vol. 16, pp 190-203, avril

[11] Hopkins A (2007) Thinking about Process Safety Indicators

[12] Wesley CM, Burns AF (1938) Statistical Indicators of Cyclical, Geoffrey H. Moore, ed. 